\title{
Simulation study of the biodiesel production from palm fatty acid distillate using palm empty fruit bunch catalyst in reactive distillation column
}

\author{
Arif Hidayat* and Bachrun Sutrisno \\ Chemical Engineering Department, Universitas Islam Indonesia, Indonesia
}

\begin{abstract}
In this paper, the simulation study of biodiesel production from Palm Fatty Acid Distillate (PFAD) using Palm Empty Fruit Bunch (PEFB) catalyst as the heterogeneous acid catalyst in reactive distillation (RD) column was studied. The main parameters of the basic RD column such as the number of stages, molar ratio of feed, total number of stages, and reboiler heat duty were employed in the simulation study. The equilibrium stage and rate-based models were used for the RD simulation studies. The simulation studies show that the equilibrium stage model could describe the column profiles only qualitatively while the rate-based model was capable in describing the column profiles quantitatively and qualitatively. From simulation results, it can be concluded that the reactive distillation process with the Palm Empty Fruit Bunch catalyst offered advantages over the conventional process because it could eliminate the requirement of post-processing separation and purification at cost-effective column design and operating conditions. The optimum condition for producing biodiesel by reactive distillation using PEFB catalyst was found as follows: 4:1 of methanol to PFAD molar feed ratio, reflux ratio of 1.5 , reboiler heat duty of $2.107 \mathrm{~kJ} / \mathrm{h}$ and 3 reactive stages. This condition provided a FFA conversion of $97 \mathrm{wt} \%$ and biodiesel purity of $97.5 \%$.
\end{abstract}

\section{Introduction}

Biodiesel is a mono alkyl ester of fatty acid derived from vegetable oils and animal fats. Biodiesel is conventionally produced via transesterification of triglycerides, which is the reaction of vegetable oils with alcohol to produce alkyl esters and glycerol, in the presence of an alkaline catalyst. Biodiesel can also be produced by esterification of free fatty acid (FFA) with alcohol to fattyacid alkyl ester (biodiesel) and water (byproduct). The main advantages of using biodiesel are, it provide lower hydrocarbon and carbon monoxide emissions, higher cetane numbers, less smoke and particulates, provide engine lubricity to low sulfur diesel fuels and are biodegradable and nontoxic.

One of the major concern for biodiesel production is economic feasibility. The overall biodiesel cost consists of raw material (production and processing), catalyst, biodiesel processing (energy consumables and labour), transportation (raw materials and final products) and taxes [1]. To date, most biodiesel plants are using refined vegetable oils as their main feedstock. However, these feedstock is impractical and uneconomical due to high feedstock cost and priority as food resources. Therefore, the cost of refined vegetable oils contributed nearly $80 \%$ of the overall biodiesel production cost. The use of low cost feedstocks such as Palm Fatty Acid Distillate (PFAD) can reduce biodiesel production cost and increase supply while avoiding the food versus fuel problem. Meanwhile, carbon-based solid acids are considered ideal catalysts for many reactions due to their chemical inertness, stable under acidic basic conditions, have very high surface area, renewable biomass sources, and good mechanical and thermal stability [2].

Biodiesel is currently produced in batch processes [3] However, using batch process for biodiesel production have many major drawbacks, such as: high alcohol demand required to shift equilibrium towards fatty esters, advanced process for catalyst neutralization which produce a salt product waste, high separation costs of fatty ester products from the reaction products, high costs caused by complex processes including multiple reactors and separation units. Therefore, to solve these problems, in recent years several researchers have developed a sustainable biodiesel production process based on reactive distillation [4].

Reactive Distillation is the process in which chemical reaction and distillation separation are carried out in one equipment. The reactive distillation process offers several benefits over conventional processes in which the reaction and the product separation are done in series, especially for reactions limited by equilibrium constraints such as esterification reaction (Equation 1).

Under these above conditions, the reaction was assumed to be pseudohomogeneous, second-order in the forward and reverse direction. The reaction rate can be described as:

$$
\mathrm{R}_{1}-\mathrm{COOH}+\mathrm{R}-\mathrm{OH} \Leftrightarrow \mathrm{R}_{1}-\mathrm{COO}-\mathrm{R}+\mathrm{H}_{2} \mathrm{O}
$$

* Corresponding author: arif.hidayat@uii.ac.id 
From this reaction, fatty acid is reacted with methanol to produce biodiesel and water and the reaction is reversible. Therefore, conversion of the reaction is limited by the concentration of products. In order to control the reaction in forward direction, removal of biodiesel and water from the system is important. As the biodiesel and water in reactive distillation are continuously separated from the reaction zone, no limiting chemical equilibrium can be established and thus the reaction velocity is maintained at a high rate, resulting in greater yields. Other benefits of reactive distillation can include the minimization of side reactions and the utilization of the heat of reaction for the mass transfer within the same column. Therefore the capital investment and operating costs are significantly lower with reactive distillation than for conventional processes. Examples for successful applications of reactive distillation have, among others, been reported for esterifications, etherifications, alkylations and isomerizations [5].

In recent literatures, many works about reactive distillation can be found. He et al. (2006) explored the biodiesel production by reactive distillation from canola oil and methanol using potassium hydroxide as catalyst. Kumar and Mahajani (2007) studied the production of biodiesel by esterification of lactic acid with n-butanol by reactive distillation. Bock et al. (1997) conducted experimental production of myristic acid with isopropanol by using homogenous acid-based catalysts such as sulfuric acid in a two-column facility. Steinigeweg and Gmehling (2003) developed a technically optimized reactive distillation process for the production of decanoic acid methyl esters by esterification of decanoic acid and methanol using Amberlystas heterogeneous catalysts. Conceptual design of RD column to produce 2-ethylhexyl dodecanoate using sulfated zirconia as a solid acid catalyst was investigated by Omota et al. (2003). Bhatia et al. (2006) carried out esterification of palmitic acid (PA) with isopropanol to make isopropyl palmitate (IPA) in a pilot plant scale obtaining high conversion. Singh et al. (2004) investigated biodiesel production from canola oil and methanol using potassium hydroxide as catalyst by reactive distillation.

To best our knowledge, no reports were found on biodiesel production from PFAD by using PEFB catalyst in a reactive distillation column. The present work focused on the operating parameters that affected esterification of PFAD with methanol in a continuous reactive distillation column. The aim of this study was to understand the relationship between operating conditions and the response FFA conversion. Furthermore, the effect of various operating conditions on the performance of the reactive distillation for biodiesel production is investigated.

\section{Simulation Study}

Figure 1 presents the process flowsheet. The flowsheet was simulated by means of a chemical process simulator (ASPEN plus V 7.4). The key equipment is the reactive distillation (RD) column. This contains in principle three zones, rectifying, reaction and stripping zone. The RD column was simulated using the RADFRAC module of Aspen Plus, which relies on the equilibrium stage model. The RADFRAC is a physical equilibrium stage model able to solve the set of equations that describe each equilibrium stage: material balances, enthalpy balances and phase equilibrium relations between the vapour and the liquid leaving the stage. The RADFAC model has been extensively used in RD and model is based on assumption that the vapor from the stage below and liquid from the stage above are brought into intimate and well-mixed contact on the stage. The vapor and liquid streams leaving the stage are assumed to be in equilibrium with each other and the overall reactive distillation process is modeled as a sequence of these equilibrium stages.

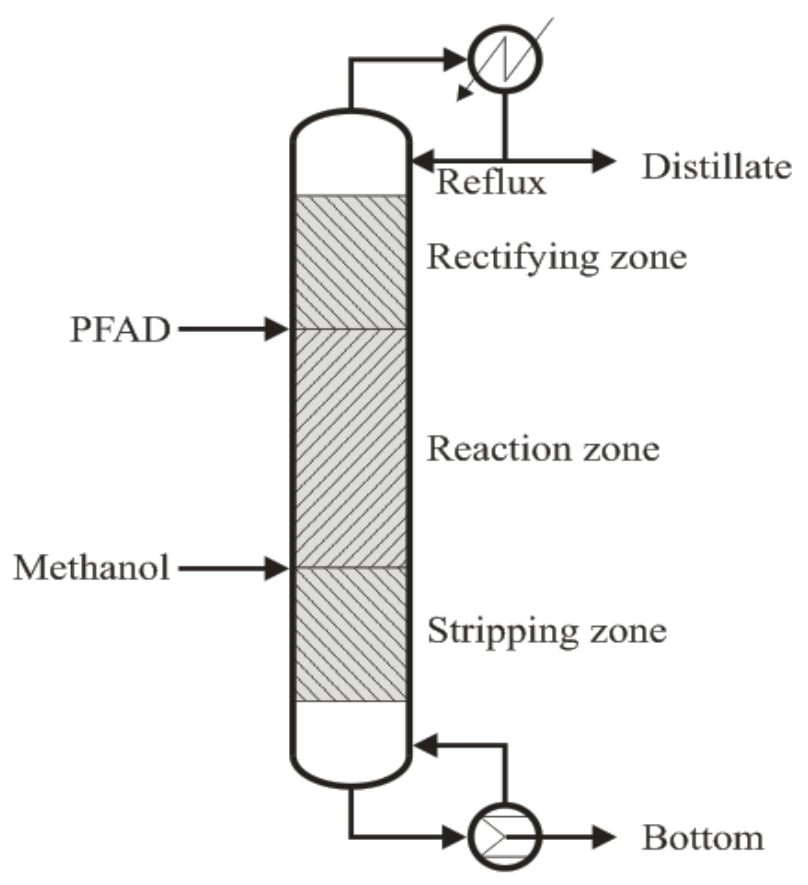

Fig. 1. Process flowsheet for RD column of free fatty acid esterification.

The catalyst used in the model column is PEFB catalyst and kinetics data of esterification reaction of FFA with methanol used in the model is applied from Hidayat's report [2]. The kinetic model of this work was built on the following assumptions: (a) the rate of the non-catalyzed reactions is negligible compared with the catalyzed reactions; (b) the catalytic activity of all sites on the catalyst surface is the same; (c) the reaction mixture can be considered as a pseudo-homogeneous system where there is no mass transfer limitation. This can be expected due to high agitation intensity and a high dissolving power of alcohol in oils; (d) the overall process kinetics is chemically controlled; (e) the reaction mixture is perfectly mixed, ensuring its uniform composition. The power law kinetics model is used to represent the reaction in Equation (1) with $\mathrm{k}$ (kinetics factor) and $\mathrm{E}$ (activation energy) of $1.432 \times 1011 \mathrm{kmol} \cdot \mathrm{m}^{-3} \cdot \mathrm{s}^{-1}$ and $5.188 \times 104$ $\mathrm{kJ} . \mathrm{kmol}^{-1}$, respectively. The thermodynamic model was the non-random two-liquid (NRTL) model. The temperature of the reactive zone was limited by the boiling temperature of the methanol $\left(64.7^{\circ} \mathrm{C}\right)$. Details about the RD column design are given in Table 1. 
Table 1. Rate constant at different temperatures.

\begin{tabular}{|c|c|}
\hline Parameter & Value \\
\hline Total number of stages & 20 \\
\hline Number of reactive stages & 3 (from 3 to 5) \\
\hline PFAD feed stage & Stage 5 at $60^{\circ} \mathrm{C}$ \\
\hline Methanol feed stage & Stage 3 \\
\hline Methanol to PFAD molar ratio & $4: 1$ \\
\hline Total feed of reactants & 50 mol/h \\
\hline Distillate to feed ratio & 0.75 \\
\hline Type of condenser (stage 1) & Total \\
\hline Type of reboiler (stage 10) & Kettle \\
\hline
\end{tabular}

\section{Results and Discussion}

\subsection{Basic RD}

At the standard condition, the feed streams consisting of PFAD and methanol at the flow rates of 10 and $40 \mathrm{kmol} / \mathrm{h}$, respectively, are separately fed to a $\mathrm{RD}$ column. The column is operated at pressure of $1 \mathrm{~atm}$ with the reflux ratio of 3 , and feed temperature of $60{ }^{\circ} \mathrm{C}$. The residence time in the column is $\sim 10 \mathrm{~min}$, much less than the retention times of 60-90 min in the conventional processes reported $[13,14]$. To reduce the amount of PFAD in the final product, the fatty acid is fed above and methanol below the reactive zone, respectively. The composition and temperature profiles in the basic $\mathrm{RD}$ column are shown in Figure 2.There is a large amount of methanol and water at the top of the column, whereas less biodiesel are observed. The bottom products consist of mostly fatty acid methyl ester (biodiesel product). Under the basic RD column, the conversion of FFA is $91.22 \%$ and the purity of biodiesel is $99.16 \%$. This was an indication that effective reaction conversion and separation were achieved in the column. The unreacted methanol, the lowest-boiling point substance, is withdrawn from the reactive distillation column as a distillate stream. As can be seen from the temperature profile shown in Figure 2, the temperature of the stage near the PFAD feed section was found to be low. This was due to the reflux flow effects. The temperature gradient was increased from tray 2 to the reboiler section.

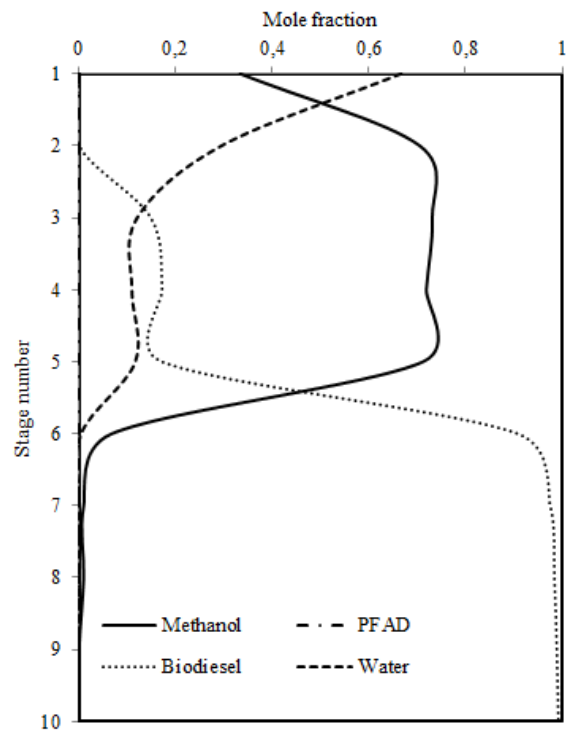

(a)

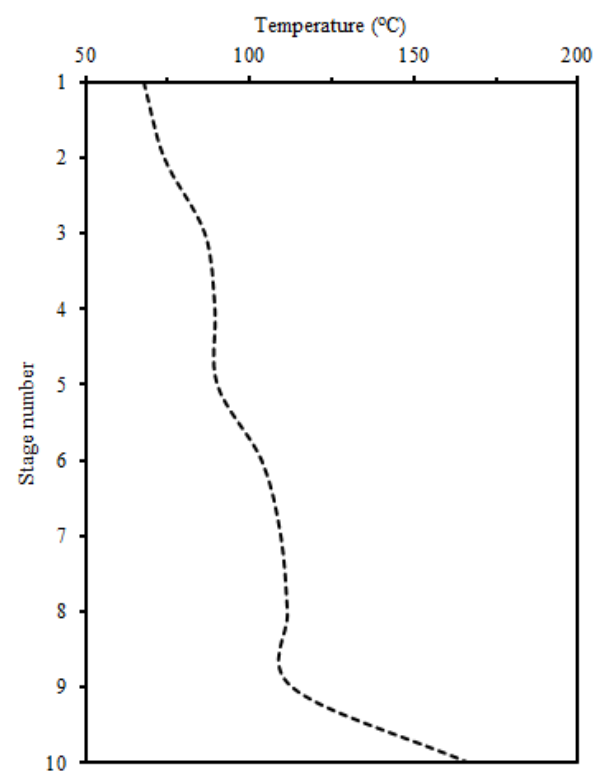

(b)

Fig. 2. Liquid compositons (a) and temperature (b) profiles along the basic RD unit.

\subsection{Effect of Molar Feed Ratio of Methanol and PFAD}

The molar feed ratio of methanol and PFAD is one of the key parameters on the performance of the RD column. Figure 3 shows the effect of molar feed ratio of methanol to PFAD on the conversion of FFA. Figure 3 shows the effect of molar feed ratio methanol to PFAD ratio on FFA conversion in the product. Increase methanol to PFAD molar ratio from $3: 1$ to $4: 1$ increases the FFA conversion in the product from $76.67 \%$ to $81.22 \%$ and increase from $82.67 \%$ to $82.91 \%$ when molar feed ratio methanol to PFAD molar ratio increases from $5: 1$ to 6 : 1. The simulation results demonstrate that the conversion of FFA increase with increasing feed molar ratio. Methanol to PFAD feed molar ratio of 4 is therefore suggested because too low amount of methanol to PFAD 
feed molar ratio would cause biodiesel product to be operated under severe conditions and even of specifications below the standards. However, increasing the effect of molar feed ratio of methanol to PFAD increased the energy consumption because of higher condenser and reboiler duties. Yield and purity of biodiesel were found to increase with increasing methanol to PFAD feed molar ratio. Total energy usage in the process increased with methanol to PFAD feed molar ratio due to additional energy consumed to heat methanol. Methanol to PFAD feed molar ratio of 4 was found suitable condition tomeet biodiesel standard values $(>96.5 \%)$ at reduced energy onsumption [15].

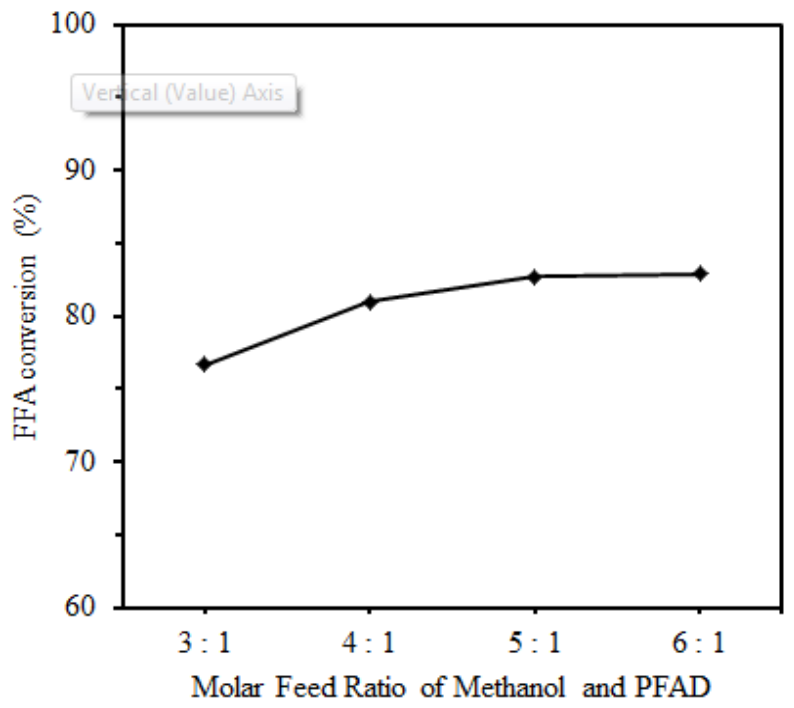

Fig. 3. Effect of molar feed ratio of methanol and oil on conversion of FFA.

\subsection{Effect of a Number of Stages}

Figure 4 demonstrates the effect of changing the number of stages on the reactive distillation performance when the feed ratio of methanol and PFAD is $4: 1$. It is noted that the esterification reaction is carried out at reaction zone (stage 3 to 5 of the column). The results indicate that adding more stages improves the system performance. The biodiesel purity reached $97.34 \%$ at number of 10 thstages. When the number of stages increase at 15 and 20 , the biodiesel purity were obtained at $98.67 \%$ and $98.93 \%$, respectively. Increasing the stages causes the separation of product from unreacted reactant more complete, thereby enhancing the biodiesel purity. Biodiesel yield and purity significantly increased by adding more number of stages owing to more contacting area and residence times in the separation zone [16]. It is noticed that the performance of the reactive distillation is slightly improved when a number of the stages are higher than 15 .

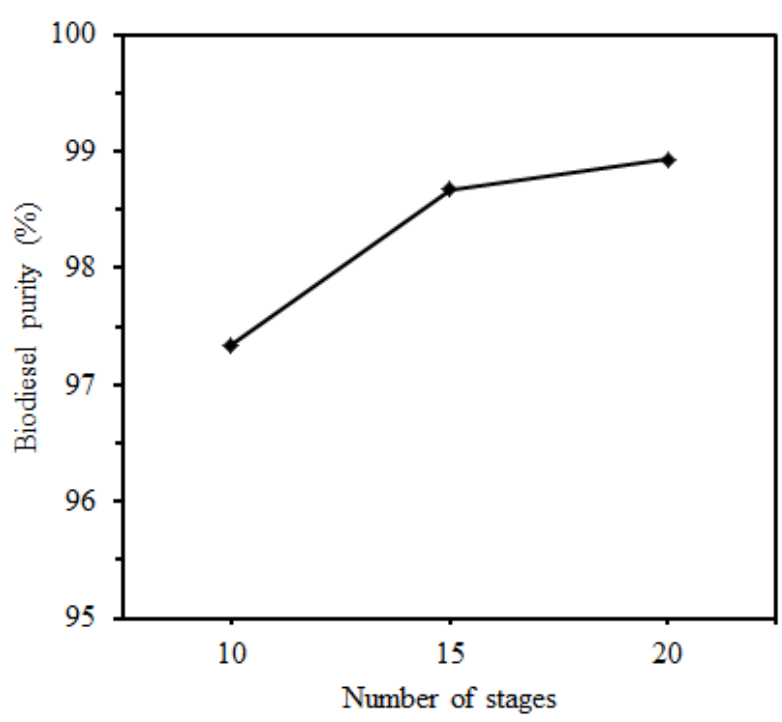

Fig. 4. Effect of Number of Stages on Biodiesel Purity.

\subsection{Effect of Feed Location of Methanol}

The location of a feed stream is an important design parameter having an effect on a reactive distillation performance. In general, a lighter reactant should be fed on the bottom stage of the reactive zone, whereas a heavier reactant is fed on the top stage of the reactive zone. When moving the feed stage of methanol, the number of reactive zone would be change. Due to large differences in the boiling temperatures between methanol and other components of the reaction mixture therefore small rectifying stage is required in order to obtain pure methanol as distillate. From the simulation results, moving the feed stage of methanol down to the bottom of the reactive distillation column decreases the conversion of FFA as shown in Figure 5.

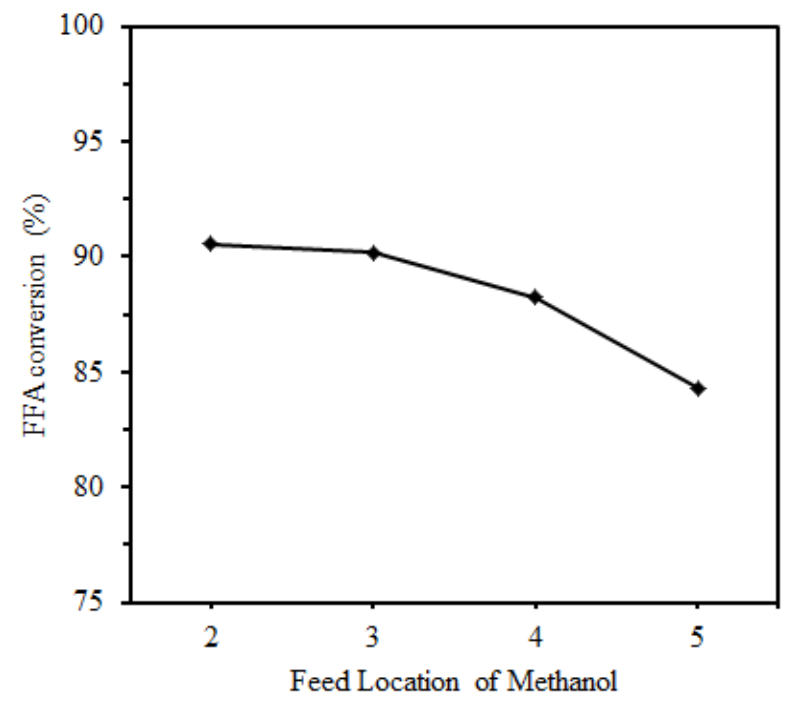

Fig. 5. Effect of Feed Location of Methanol on Conversion of FFA.

\subsection{Effect of reflux ratio and reboiler heat duty}

Increasing the reboiler duty from 1 to $1.5 .107 \mathrm{~kJ} / \mathrm{h}$ increases the FFA conversion due to vaporization of 
methanol in the column, thereby lowering methanol availability in the liquid phase of the reaction zone. Figure 6 shows that the maximum FFA conversion of $97.81 \%$ was achieved with the reboiler duty set on $2 \mathrm{~kJ} / \mathrm{h}$. The purity of biodiesel, as shown in Figure 6, increased with the reboiler duty owing to lower liquid holdups of methanol in the bottom streams. Nevertheless, the reboiler duty obviously increased the energy consumption in the process directly as seen in Figure 6. The operation of reactive distillation at reboiler heat duty of $2 \mathrm{~kJ} / \mathrm{h}$ has given high biodiesel purity, assuming no thermal decomposition of biodiesel. This is due to the large amount of methanol in the distillate stream being removed from the column.

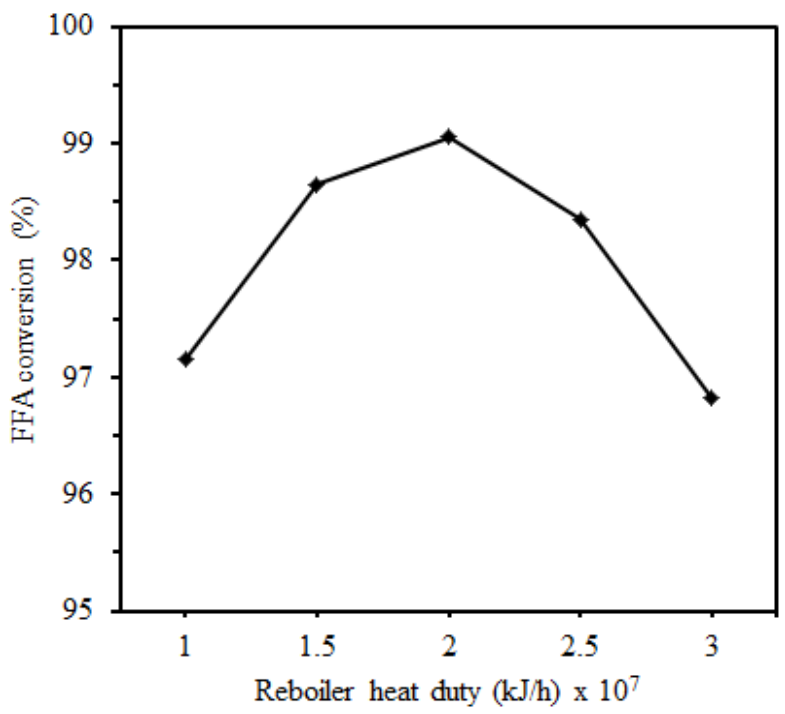

Fig. 6. Effect of reboiler heat duty on conversion of FFA.

\section{Conclusions}

Biodiesel production from esterification of FFA on PFAD with methanol by using reactive distillation (RD) was investigated. The use of $\mathrm{RD}$ along with PEFB catalyst was found beneficial over the conventional process of sequential esterification and separation. The optimum condition for producing biodiesel by reactive distillation using PEFB catalyst was found as follows: 4:1 of methanol to PFAD molar feed ratio, reflux ratio of 1.5 , reboiler heat duty of $2.107 \mathrm{~kJ} / \mathrm{h}$ and 3 reactive stages. This condition provided a FFA conversion of $97 \mathrm{wt} \%$ and biodiesel purity of $97.81 \%$. From simulation results, it can be concluded that the reactive distillation process with the heterogeneous catalyst offered advantages over the conventional process because it could eliminate the requirement of post-processing separation and purification at cost-effective column design and operating conditions. The reactive distillation process provided higher yield and purity of biodiesel than the conventional process and required much less energy consumption. The use of reactive distillation with heterogeneous catalysts eliminated many operation steps such as neutralization, washing, separation, recovery, and waste disposal operations.
The adsorption experiments indicated that modified coal fly ash was effective in removing of Remazol Blue. The percentage removal of dyes increased while the modified fly ash dosage increased. The percentage removal of dyes increased with decreased initial

\section{References}

1. A. Hidayat, B. Sutrisno, AIP Conference Proceedings, 1840, 050001, (2017)

2. A. Hidayat, Rochmadi, K. Wijaya, A. Budiman, AIP Conference Proceedings, 1699, 050005 (2015)

3. A. Hidayat, Rochmadi, K. Wijaya, A. Budiman,, IOP Conference Series: Materials Science and Engineering, 105 (1), 012026

4. Z. Mufrodi, Rochmadi, Sutijan, A. Budiman, Engineering Journal, 19 (2), 29-39 (2013)

5. R.D. Kusumaningtyas, Rochmadi, S. Purwono, A. Budiman, Int. J. Exergy, 15 (4), 447-467 (2014)

6. B.B. He, A.P. Singh, J.C.A. Thompson, Trans ASAE, 49, 107-112 (2006)

7. R. Kumar, S.M. Mahajani, Ind. Eng. Chem. Res., 46, 6873-6882 (2007)

8. H. Bock, G. Wozny, B. Gutsche, Chem. Eng. Process.: Process Intensif, 36, 101-109 (1997)

9. S. Steinigeweg, J. Gmehling, Ind. Eng. Chem. Res., 42 (15), 3612-3619 (2003)

10. F. Omota, A.C. Dimian, A. Bliek, Chem. Eng. Sci., 58, 3159-3174 (2003)

11. S. Bhatia, A.L. Ahmad, A.R. Mohamed, S.Y.Chin, Chem. Eng. Sci., 61, 7436-7477 (2006)

12. A.P. Singh, B.B. He, J.C. Thompson, Proceedings of the ASAE/CSAE annual international meeting, Ottawa, Canada (2004)

13. D. Darnoko, M. Cheryan, J Am Oil Chem Soc, 77, 1269-1272 (2000)

14. H. Noureddini, D. Harkey, V. Medikonduru, J Am Oil Chem Soc, 75, 1775-1783 (1998)

15. N. Boon-anuwat, W. Kiatkittipong, F. Aiouache, S. Assabumrungrat, Chem. Eng. Process.: Process Intensif, 92, 33-44 (2015)

16. L. Simasatitkul, P.Siricharnsakunchai, Y. Patcharavorachot, S. Assabumrungrat, A. Arpornwichanop, Korean J Chem Eng, 28 (3), 649655 (2011) 